\title{
Echocardiographic differentiation of hypertensive heart disease and hypertrophic cardiomyopathy ${ }^{\star}$
}

\author{
YOSHINORI L DOI, JOHN E DEANFIELD, WILLIAM J MCKENNA†, \\ HENRY J DARGIE, CELIA M OAKLEY, JOHN F GOODWIN \\ From the Division of Cardiovascular Disease (Clinical Cardiology), Royal Postgraduate Medical School, \\ Hammersmith Hospital, London
}

SUMMARY The clinical differentiation of hypertensive heart disease from hypertrophic cardiomyopathy usually presents no problem but it is less clear whether an echocardiographic distinction can always be made and, if so, what those echocardiographic criteria of difference are. It can be inferred from recent publications that when echocardiographic criteria for hypertrophic cardiomyopathy are met in hypertensive subjects, both diagnoses may be made. This may be unjustified, and in order to clarify this problem the $M$-mode echocardiographic features of 37 patients with severe systemic hypertension were compared with those of 70 patients with hypertrophic cardiomyopathy and normal blood pressure.

Systolic anterior movement of the mitral valve and/or mid-systolic closure of the aortic valve were found in 82 per cent of patients with obstructive and 35 per cent of patients with non-obstructive hypertrophic cardiomyopathy. These features were not seen in patients with hypertension. The conventional echocardiographic features of left ventricular hypertrophy and function did not permit distinction between hypertensive heart disease and hypertrophic cardiomyopathy.

The echocardiographic diagnosis of hypertensive heart disease from hypertrophic cardiomyopathy is, therefore, difficult unless systolic anterior movement of the mitral valve and/or mid-systolic closure of the aortic valve can be shown.

Echocardiography is a useful procedure in the diagnosis of hypertrophic cardiomyopathy and the presence of asymmetric septal hypertrophy (septal thickness to left ventricular posterior wall ratio $\geqslant 1.3$ ) has, in particular, been considered to be pathognomonic for hypertrophic cardiomyopathy. ${ }^{1}$ Subsequently asymmetric septal hypertrophy has been found in many other conditions including hypertension. ${ }^{2-11}$ Though earlier reports suggested that the hypertensive heart could be differentiated from hypertrophic cardiomyopathy using echocardiography, ${ }^{12}$ difficulties have been observed when asymmetric septal hypertrophy (the ratio $\geqslant 1 \cdot 3$ ) is the diagnostic criterion. ${ }^{8-11}$ Moreover, the classical echocardiographic features of hypertrophic cardiomyopathy, including asymmetric septal hypertrophy, have been reanalysed recently and it has been shown that no single $M$-mode echocardiographic feature is consistently abnormal in hypertrophic cardiomyopathy. ${ }^{13}$ We have therefore * This work was supported by a grant from the British Heart Foundation.

†Research fellow of the Medical Research Council of Canada.

Received for publication 11 February 1980 assessed the M-mode echocardiogram for any features which may differentiate hypertensive heart disease and hypertrophic cardiomyopathy.

\section{Subjects and methods}

Thirty-seven patients with severe systemic hypertension were studied by $M$-mode echocardiography. The echocardiographic features of these patients were compared with those of 70 patients with hypertrophic cardiomyopathy and 37 normal controls.

The patients with systemic hypertension all had a resting diastolic blood pressure of $120 \mathrm{mmHg}$ or more before treatment. All had electrocardiographic evidence of left ventricular hypertrophy with gross ST-T changes. None of these hypertensive patients was in left ventricular failure nor did they have any clinical evidence of left ventricular outflow tract obstruction or coronary artery disease: cardiac catheterisation had not been performed. All patients were on diuretics, beta-adrenergic blocking drugs, methyldopa, minoxidil, or a combination of these 
drugs. There were 17 men and 20 women, age range 20 to 69 , mean 46 years.

The patients with hypertrophic cardiomyopathy were all normotensive and had clinical and angiographic evidence of hypertrophic cardiomyopathy. ${ }^{14}$ They were considered to have obstruction if the left ventricular outflow tract gradient at rest or after provocation (with amyl nitrite inhalation or the Valsalva manoeuvre) was equal to or greater than $20 \mathrm{mmHg}$; 48 patients had resting or provocable obstruction, while 22 patients had no obstruction. There were $\mathbf{4 2}$ male and 28 female patients, ranging in age from 12 to 70 , mean 44 years.

Thirty-seven normal controls were studied, 14 men and 23 women, age range 20 to 60 , mean 34 years.

\section{ECHOCARDIOGRAM}

Left ventricular, mitral valve leaflet, aortic root, and left atrial echocardiograms were obtained by standard methods, ${ }^{15}$ using an Ekoline 20 ultrasonoscope with a $2.25 \mathrm{MHz}$ transducer, having a repetition frequency of 1000 pulses per second. The output was displayed on a Cambridge strip chart recorder with a simultaneous electrocardiogram. Studies were made with subjects supine or in a partial left lateral position, with the transducer at the left sternal edge.

The following echocardiographic features were assessed (Fig. 1 and 2): (1) ventricular septal thick-

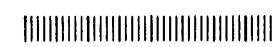
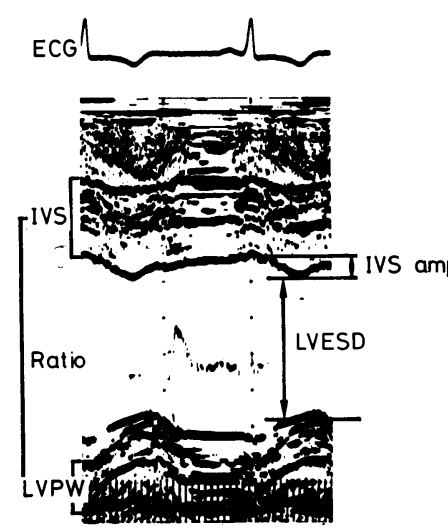

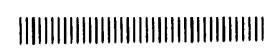

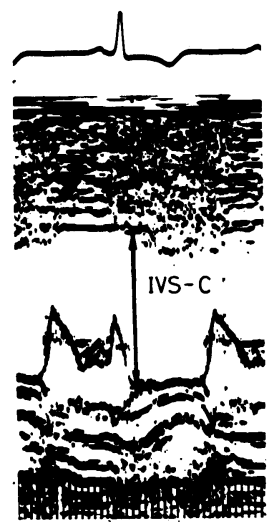

Fig. 1 The echocardiographic features assessed. IVS, ventricular septal thickness; ratio, septal thickness to left ventricular posterior wall (LVPW) ratio; IVS amp, septal amplitude of motion; LVESD, left ventricular end-systolic dimension; IVS-C, septal-mitral valve distance at the onset of systole; ECG, electrocardiogram.

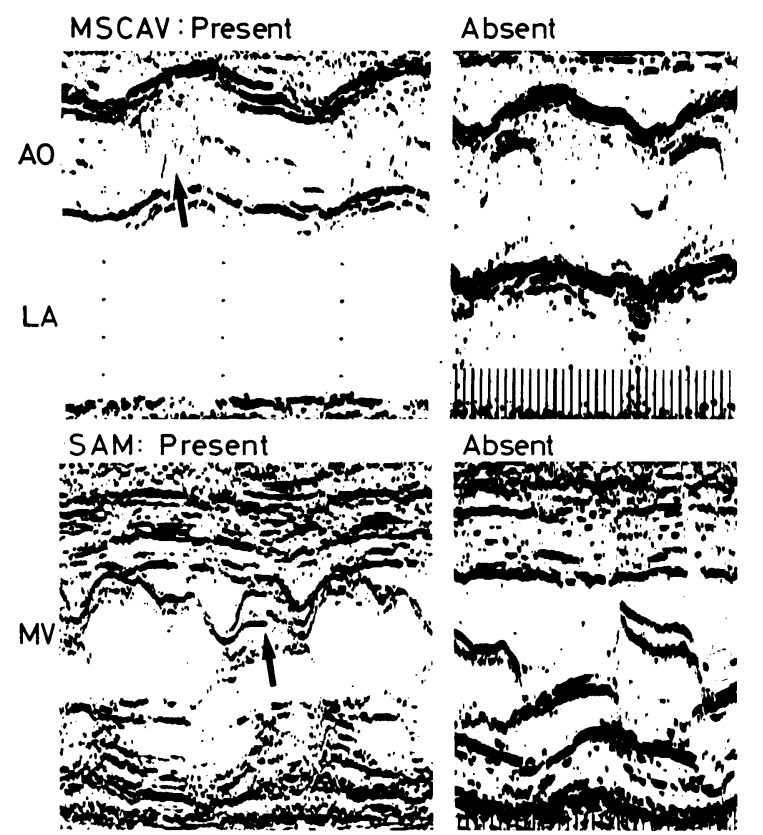

Fig. 2 The echocardiographic features assessed. MSCAV, mid-systolic closure of the aortic valve; $S A M$, systolic anterior movement of the mitral valve; $A O$, aortic root; $L A$, left atrium; $M V$, mitral valve.

ness at end-diastole, (2) ventricular septal amplitude of motion, (3) ventricular septal thickness to left ventricular posterior wall ratio, (4) left ventricular end-systolic dimension, (5) septal-mitral valve distance at the onset of systole, (6) presence or absence of systolic anterior movement of the mitral valve, and (7) mid-systolic closure of the aortic valve. Features (1) to (4) were assessed from the echocardiograms obtained just below the plane of the mitral valve, where the minor axis of the left ventricle was recorded. Features (5) and (6) were assessed from the echocardiograms obtained at the plane of the mitral valve tips where both anterior and posterior leaflets were recorded simultaneously. Feature (7) was assessed from the echocardiograms obtained at the plane of the aortic root and the left atrium where both anterior and posterior aortic cusps were visualised.

STATISTICAL ANALYSIS

Standard statistical analyses were performed. One way analysis of variance was performed initially to test the difference between means of more than two groups; when significant, a two-sample Wilcoxon test was used because the data were not normally distributed. 


\section{Results}

The results for the seven features analysed are shown in the Table.

\section{HYPERTENSIVE HEART COMPARED WITH \\ NORMAL HEART}

The median ventricular septal thickness and ventricular septal thickness to posterior wall ratio in hypertension were significantly greater than in normal controls $(p<0.001)$. The other features were not significantly different, but no normal control or hypertensive patient showed systolic anterior movement of the mitral valve or mid-systolic closure of the aortic valve.

\section{HYPERTENSIVE HEART COMPARED WITH HYPERTROPHIC OBSTRUCTIVE \\ CARDIOMYOPATHY}

The median ventricular septal thickness and ventricular septal thickness to posterior wall ratio in hypertension were significantly less than in hypertrophic obstructive cardiomyopathy $(\mathrm{p}<0.001)$ (Fig. 3). The median ventricular septal amplitude of motion, septal-mitral valve distance at the onset of systole, and left ventricular enddiastolic dimension were all significantly greater in hypertension than in hypertrophic obstructive cardiomyopathy $(\mathrm{p}<0.001, \mathrm{p}<0.001$, and $\mathrm{p}<0.05$, respectively). Of 47 patients with hypertrophic

Table Echocardiographic data

\begin{tabular}{|c|c|c|c|c|}
\hline & Normal & Hypertension & $\begin{array}{l}\text { Non- } \\
\text { obstructive } \\
H C M\end{array}$ & $\begin{array}{l}\text { Obstructive } \\
\text { HCM }\end{array}$ \\
\hline \multicolumn{5}{|l|}{ IVS } \\
\hline $\begin{array}{l}\text { thickness } \\
(\mathrm{mm})\end{array}$ & $\begin{array}{l}10 \cdot 0 \\
(9 \cdot 0-10 \cdot 0)\end{array}$ & $\begin{array}{l}14 \cdot 0 \\
(13 \cdot 0-16 \cdot 0)\end{array}$ & $\begin{array}{l}14 \cdot 0 \\
(12 \cdot 0-19 \cdot 0)\end{array}$ & $\begin{array}{l}19 \cdot 0 \\
(17 \cdot 0-22 \cdot 0)\end{array}$ \\
\hline \multicolumn{5}{|l|}{ IVS } \\
\hline $\begin{array}{l}\text { amplitude } \\
\text { (mm) }\end{array}$ & $\begin{array}{l}7 \cdot 0 \\
(6 \cdot 0-8 \cdot 0)\end{array}$ & $\begin{array}{l}7 \cdot 0 \\
(6 \cdot 0-8 \cdot 0)\end{array}$ & $\begin{array}{c}5 \cdot 0 \\
(4 \cdot 0-6 \cdot 0)\end{array}$ & $\begin{array}{l}4 \cdot 0 \\
(4 \cdot 0-5 \cdot 0)\end{array}$ \\
\hline $\begin{array}{l}\text { IVS } / \text { LVPW } \\
\text { ratio }\end{array}$ & $\begin{array}{l}1 \cdot 1 \\
(1 \cdot 1-1 \cdot 2)\end{array}$ & $\begin{array}{l}1 \cdot 4 \\
(1 \cdot 3-1 \cdot 5)\end{array}$ & $\begin{array}{l}1 \cdot 75 \\
(1 \cdot 5-2 \cdot 1)\end{array}$ & $\begin{array}{l}2 \cdot 0 \\
(1 \cdot 8-2 \cdot 3)\end{array}$ \\
\hline $\begin{array}{l}\text { IVS-C } \\
\quad(\mathrm{mm})\end{array}$ & $\begin{array}{l}31 \cdot 0 \\
(29 \cdot 0-34 \cdot 0)\end{array}$ & $\begin{array}{l}30 \cdot 0 \\
(28 \cdot 0-31 \cdot 0)\end{array}$ & $\begin{array}{l}24 \cdot 5 \\
(21 \cdot 0-29 \cdot 0)\end{array}$ & $\begin{array}{l}21 \cdot 0 \\
(19 \cdot 0-23 \cdot 0)\end{array}$ \\
\hline $\begin{array}{l}\text { LVESD } \\
\quad(\mathrm{mm})\end{array}$ & $\begin{array}{l}28 \cdot 0 \\
(27 \cdot 0-29 \cdot 0)\end{array}$ & $\begin{array}{l}25 \cdot 0 \\
(24 \cdot 0-30 \cdot 0)\end{array}$ & $\begin{array}{l}25 \cdot 5 \\
(22 \cdot 0-30 \cdot 0)\end{array}$ & $\begin{array}{l}24 \cdot 0 \\
(21 \cdot 0-26 \cdot 0)\end{array}$ \\
\hline SAM & $0 / 37$ cases & 0/37 cases & $6 / 22$ cases & $36 / 47$ cases \\
\hline MSCAV & $0 / 37$ cases & $0 / 37$ cases & $3 / 14$ cases & $27 / 35$ cases \\
\hline
\end{tabular}

HCM, hypertrophic cardiomyopathy; IVS, ventricular septum; LVPW, left ventricular posterior wall; IVS-C, septal-mitral valve distance at the onset of systole; LVESD, left ventricular endsystolic dimension; SAM, systolic anterior movement of the mitral valve; MSCAV, mid-systolic closure of the aortic valve. Figures in parentheses, $95 \%$ confidence for the median.

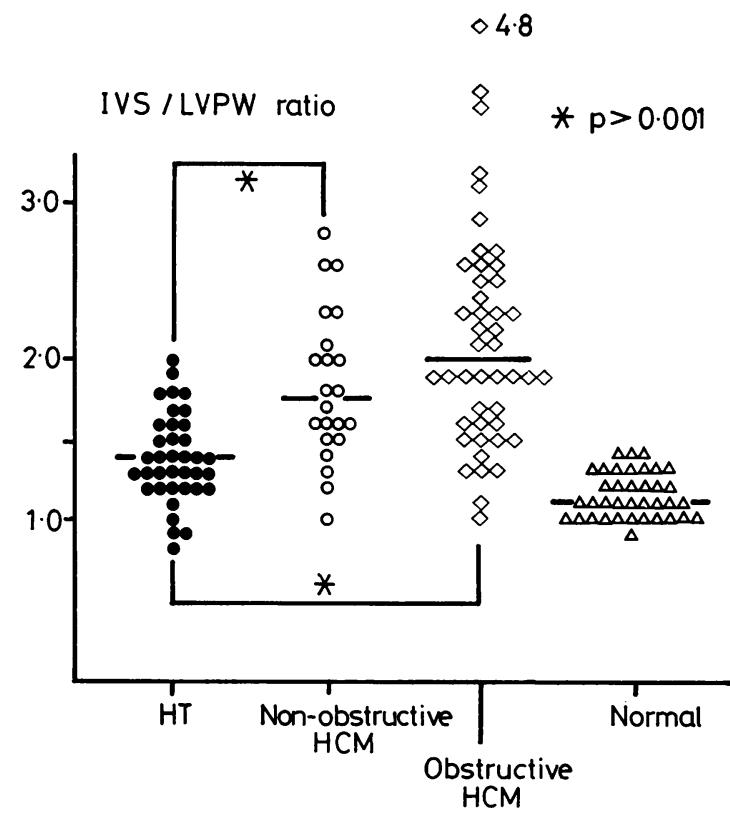

Fig. 3 Ventricular septal thickness (IVS) to left ventricular posterior wall (LVPW) ratio. HT, hypertension; HCM, hypertrophic cardiomyopathy.

obstructive cardiomyopathy, 36 had systolic anterior movement of the mitral valve and 27 of 35 patients had mid-systolic closure of the aortic valve. In 13 patients, the occurrence of mid-systolic closure of the aortic valve could not be adequately assessed.

\section{HYPERTENSIVE HEART COMPARED WITH HYPERTROPHIC NON-OBSTRUCTIVE CARDIOMYOPATHY}

The median ventricular septal thickness to posterior wall ratio in hypertension was significantly less than in non-obstructive hypertrophic cardiomyopathy $(p<0.001)$ (Fig. 3) and the median ventricular septal amplitude of motion and septal-mitral valve distance at the onset of systole were significantly greater than in non-obstructive hypertrophic cardiomyopathy $(p<0.001$, and $p<0.05$, respect tively) (Fig. 4 and 5). The median ventriculathickness and left ventricular end-systolic dimension were not significantly different (Fig. 6 and 7). In non-obstructive hypertrophic cardiomyopathy, six of 22 patients had systolic anterior movement of the mitral valve and three of 14 patients had midsystolic closure of the aortic valve. In eight patients, mid-systolic closure of the aortic valve could not be adequately assessed. 


\section{Discussion}

At necropsy left ventricular hypertrophy secondary to hypertension is usually regarded as symmetrical, uniformly involving the septum and the left ventricular posterior wall. ${ }^{12}$ Echocardiographic work has led to this conventional view being questioned, and asymmetric septal hypertrophy has been observed in hypertension. ${ }^{8-11}$ The present study, examining patients with severe systemic hypertension, showed increased septal thickness and increased septal thickness to posterior wall ratio compared with normal controls. This is consistent with the study of Bahler et al. ${ }^{16}$ which showed that septal thickness has a greater influence on the summated vector and SV1 + RV6 than does the thickness of the posterior wall assessed by echocardiography.

Other echocardiographic features of hypertensive patients were similar to those of normal controls. Neither systolic anterior movement of the mitral valve nor mid-systolic closure of the aortic valve were seen either in hypertensive patients or normal controls; this is consistent with the findings of Savage et al. in 234 hypertensive patients. ${ }^{17}$

Despite the reports of asymmetric septal hypertrophy in normal children, ${ }^{2}$ in athletes, ${ }^{34}$ and in many other forms of congenital and acquired heart disease, ${ }^{5-7}$ including systemic hypertension, ${ }^{8-11}$ it is still claimed that asymmetric septal hypertrophy

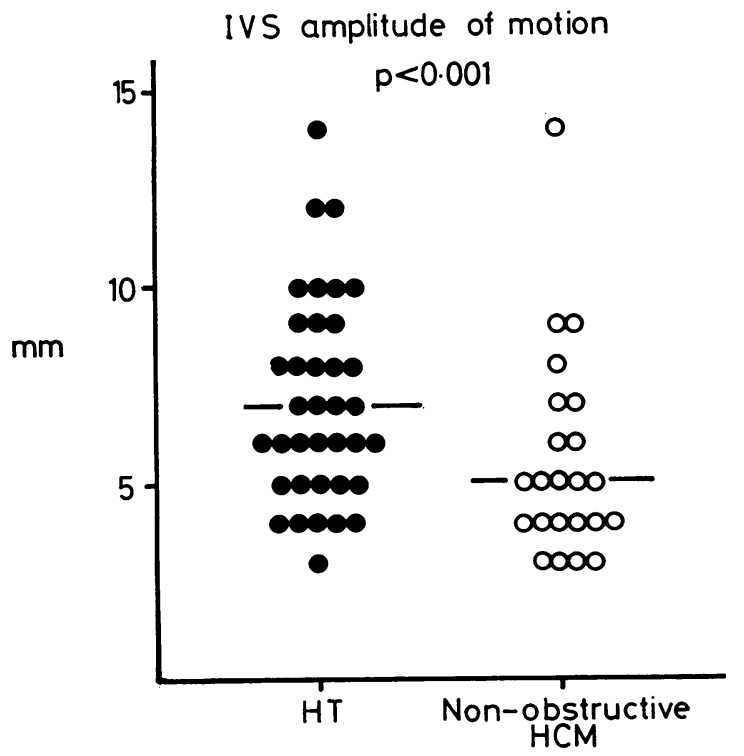

Fig. 4 Ventricular septal (IVS) amplitude of motion. $H T$, hypertension; HCM, hypertrophic cardiomyopathy.

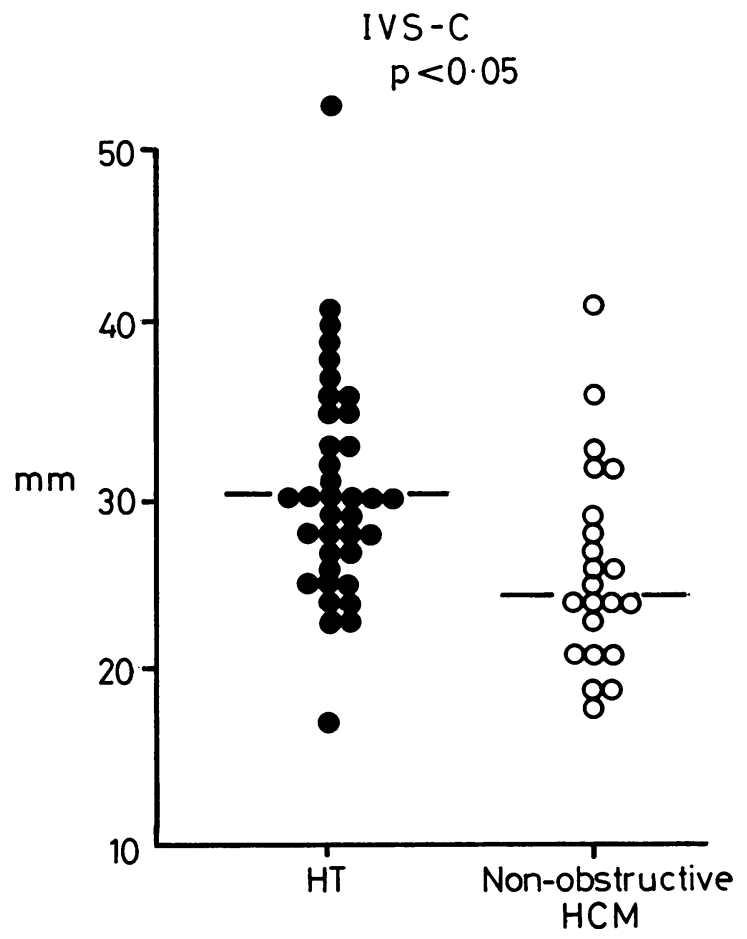

Fig. 5 Septal-mital valve distance (IVS-C) at the onset of systole. HT, hypertension; HCM, hypertrophic cardiomyopathy.

is diagnostic for hypertrophic cardiomyopathy. ${ }^{18} 19$ In our study, 70 per cent of hypertensive patients had the ratio $\geqslant 1 \cdot 3$, so clearly asymmetric septal hypertrophy is not diagnostic for hypertrophic cardiomyopathy. Other workers have found asymmetric septal hypertrophy in 4 to 47 per cent of hypertensive patients. ${ }^{8-10} 16$ All our patients had electrocardiographic evidence of severe left ventricular hypertrophy with pronounced ST-T changes and this may account for the increased incidence of asymmetric septal hypertrophy in comparison with the other studies. Though utilisation of the ratio $\geqslant 1.5$ improves the diagnostic specificity for hypertrophic cardiomyopathy, 1220 in our study 13 hypertensive patients $(35 \%)$ had such a ratio.

All the echocardiographic features measured showed significant differences between hypertension and hypertrophic obstructive cardiomyopathy (Table). The majority of patients with hypertrophic obstructive cardiomyopathy showed systolic anterior movement of the mitral valve and/or midsystolic closure of the aortic valve, and the presence of one of these two features differentiates hypertrophic obstructive cardiomyopathy from hyper- 


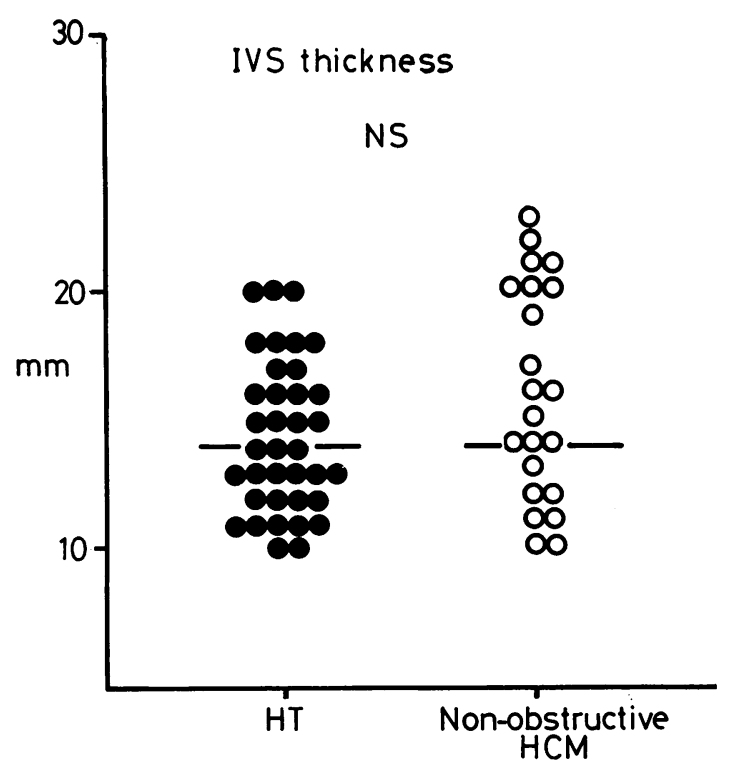

Fig. 6 Ventricular septal (IVS) thickness. $H T$, hypertension; HCM, hypertrophic cardiomyopathy.

tension. Among nine patients with hypertrophic obstructive cardiomyopathy who did not show either systolic anterior movement of the mitral valve or mid-systolic closure of the aortic valve, six had a ventricular septal thickness to left ventricular posterior wall ratio greater than 2.0 ; this was not seen in the hypertensive patients (Fig. 3). Only

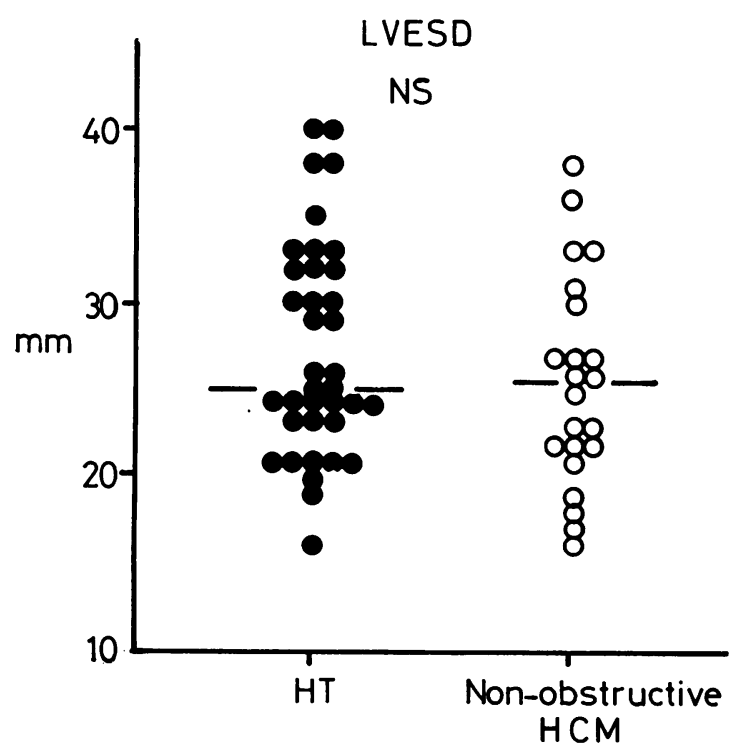

Fig. 7 Left ventricular end-systolic dimension (LVESD). $H T$, hypertension; HCM, hypertrophic cardiomyopathy. three patients $(6 \%)$ with hypertrophic obstructive cardiomyopathy, therefore, could not be differentiated from hypertensive patients.

In the patients with hypertension and those with non-obstructive hypertrophic cardiomyopathy, ventricular septal thickness and left ventricular endsystolic dimension were identical; though septal amplitude of motion, the ventricular septal thickness to left ventricular posterior wall ratio, and septalmitral valve distance at the onset of systole showed statistical difference between the median values of the two groups, the degree of overlap made differentiation of the individual patient difficult (Fig. 3 to 7). Only a small number of patients with non-obstructive hypertrophic cardiomyopathy had

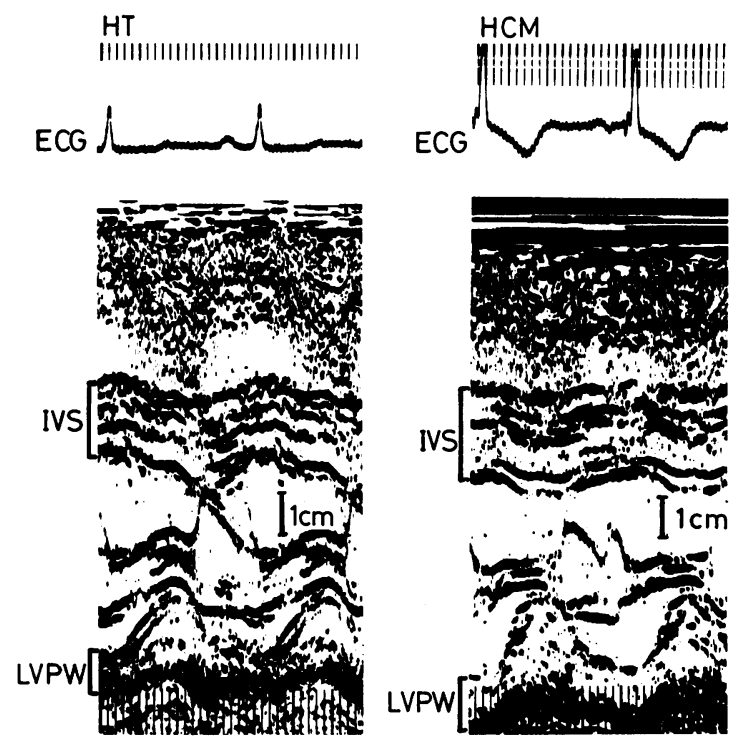

Fig. 8 Representative echocardiograms of patients with hypertension and hypertrophic cardiomyopathy. $H T$, hypertension; HCM, hypertrophic cardiomyopathy; ECG, electrocardiogram; IVS, ventricular septal thickness; LVPW, left ventricular posterior wall.

systolic anterior movement of the mitral valve or mid-systolic closure of the aortic valve. The presence of one of these two features or the ratio equal to or greater than 2.0 differentiates only 50 per cent of non-obstructive hypertrophic cardiomyopathy from hypertension. The echocardiographic differentiation of non-obstructive hypertrophic cardiomyopathy from hypertension cannot be made unless the patients with non-obstructive hypertrophic cardiomyopathy have systolic anterior movement of the mitral valve and/or mid-systolic closure of the aortic valve. 
Systemic hypertension may coexist with hypertrophic cardiomyopathy. Since the initial description of two patients with hypertension and functional obstruction of the left ventricular outflow tract by Brock, ${ }^{22}$ several investigators have reported patients with hypertrophic cardiomyopathy and hypertension. ${ }^{23-25}$ In large series, however, hypertension is usually infrequent in patients with hypertrophic cardiomyopathy ${ }^{26} 27$ (and McKenna et al., unpublished data on 216 patients). Erroneous use of conservative echocardiographic criteria may cause misdiagnosis of hypertrophic cardiomyopathy in hypertensive patients.

\section{References}

1 Henry WL, Clark CE, Epstein SE. Asymmetric septal hypertrophy: echocardiographic identification of the pathognomonic anatomic abnormality of IHSS. Circulation 1973; 47: 225-33.

2 Larter WE, Allen HD, Sahn DJ, Goldberg SJ. The asymmetrically hypertrophied septum. Further differentiation of its causes. Circulation 1976; 53: 19-27.

3 Roeske WR, O'Rourke RA, Klein A, Leopold G, Karliner JS. Noninvasive evaluation of ventricular hypertrophy in professional athletes. Circulation 1976; 53: 286-92.

4 Menapace FJ, Hammer WJ, Kessler KK, et al. Echocardiographic measurements of left ventricular wall thickness in weight lifters: a problem with the definition of ASH (abstract). Am $\mathcal{F}$ Cardiol 1977; 39: 276.

5 Maron BJ, Clark CE, Henry WL, et al. Prevalence and characteristics of disproportionate ventricular septal thickening in patients with acquired or congenital heart diseases: echocardiographic and morphologic findings. Circulation 1977; 55: 489-96.

6 Feizi Ö, Emanuel R. Echocardiographic spectrum of hypertrophic cardiomyopathy. Br Heart $\mathcal{F} 1975$; 37: 1286-302.

7 Henning H, O'Rourke RA, Crawford MH, Righetti A, Karliner JS. Inferior myocardial infarction as a cause of asymmetric septal hypertrophy. $A m \mathcal{F}$ Cardiol 1978; 41: 817-22.

8 Criley JM, Blaufuss AH, Abbasi AS. Nonobstructive IHSS (letter). Circulation 1975; 52: 963.

9 Toshima H, Koga Y, Yoshioka H, Akiyoshi T, Kimura N. Echocardiographic classification of hypertensive heart disease. Fpn Heart $\mathcal{F} 1975$; 16: 377-93.

10 Dunn FG, Chandraratna P, de Carvalho JGR, Basta LL, Frohlich ED. Pathophysiologic assessment of hypertensive heart disease with echocardiography. Am $\mathcal{F}$ Cardiol 1977; 39: 789-95.

11 Gibson DG, Traill TA, Hall RJC, Brown DJ. Echocardiographic features of secondary left ventricular hypertrophy. Br Heart $\mathcal{F}$ 1979; 41 : 54-9.

12 Abbasi AS, MacAlpin RN, Eber LM, Pearce ML.
Left ventricular hypertrophy diagnosed by echocardiography. $N$ Engl f Med 1973; 289: 118-21.

13 Doi Y, McKenna WJ, Gehrke J, Oakley CM, Goodwin JF. M-mode echocardiography in hypertrophic cardiomyopathy: diagnostic criteria and prediction of obstruction. Am $\mathcal{f}$ Cardiol 1980; 45: 6-14.

14 Cohen J, Effat H, Goodwin JF, Oakley CM, Steiner RE. Hypertrophic obstructive cardiomyopathy. $\mathrm{Br}$ Heart f 1964; 26: 16-32.

15 Feigenbaum $\mathrm{H}$. Clinical applications of echocardiography. Progr Cardiovasc Dis 1972; 14: 531-58.

16 Bahler AS, Teichholz LE, Gorlin R, Herman MV. Correlations of electrocardiography and echocardiography in determination of left ventricular wall thickness: study of apparently normal subjects. Am f Cardiol 1977; 39: 189-95.

17 Savage DD, Drayer IM, Henry WL, et al. Echocardiographic assessment of cardiac anatomy and function in hypertensive subjects. Circulation 1979; 59: 623-32.

18 Darsee JR, Heymsefield SB, Nutter DO. Hypertrophic cardiomyopathy and human leukocyte antigen linkage: differentiation of two forms of hypertrophic cardiomyopathy. $N$ Engl f Med 1979; 300: 877-82.

19 Savage DD, Seides SF, Maron BJ, Myers DJ, Epstein SE. Prevalance of arrhythmias during 24hour electrocardiographic monitoring and exercise testing in patients with obstructive and nonobstructive hypertrophic cardiomyopathy. Circulation 1979; 59: 866-75.

20 Shah PM, Sylvester LJ. Echocardiography in the diagnosis of hypertrophic obstructive cardiomyopathy. Am F Med 1977; 62: 830-5.

21 Ten Cate FJ. Asymmetric septal hypertrophy: echocardiographic manifestations. Rotterdam: BronderOffset BV, 1978: 56-7.

22 Brock RC. Functional obstruction of the left ventricle. Guy's Hosp Rep 1957; 106: 221-38.

23 Moreyra E, Knibbe P, Brest AN. Hypertension and muscular subaortic stenosis. Chest 1970; 57: 87-90.

24 Hamby RI, Roberts GS, Meron JM. Hypertension and hypertrophic subaortic stenosis. Am $\mathcal{f} \mathrm{Med}$ 1971; 51: 474-81.

25 Alday LE, Wagner HR, Vlad P. Severe systemic hypertension and muscular subaortic stenosis. $\mathrm{Am}$ Heart f 1972; 83: 395-400.

26 Braunwald E, Lambrew CT, Rockoff SD, Ross J Jr, Morrow AG. Idiopathic hypertrophic subaortic stenosis. 1. A description of the disease based upon an analysis of 64 patients. Circulation 1964; 30, suppl IV: IV 3-119.

27 Hardarson T, de la Calzada CS, Curiel R, Goodwin JF. Prognosis and mortality of hypertrophic obstructive cardiomyopathy. Lancet 1973; ii: 1462-7.

Requests for reprints to Professor J F Goodwin, Division of Cardiovascular Disease, Hammersmith Hospital, Du Cane Road, London W12 0HS. 